\title{
KETALAR (CI-581) IN PAEDIATRIC DENTISTRY: A FIELD TRIAL IN THREE ARCTIC COMMUNITIES
}

\author{
W. E. SPOEREL, M.D., F.R.C.P.(C)
}

The ARCTIC regions have been made accessible by the airplane, and commercial and military interests have brought our civilization into the North. The resulting rapid change in the living conditions of the Eskimos has produced, among other problems, a high rate of dental decay in children. Lack of dental hygiene combined with the ready supply of soft drinks and concentrated carbohydrates is the likely cause of severe decay of deciduous and often permanent teeth, proceeding to infection of the gums and abscess formation (Fig. 1). Dental care, offered at present by only one dentist on Baffin Island (population 6,000), is hampered mainly by the problem of transportation to the widely scattered settlements. Although most of them are accessible by air, weather conditions and problems with flight schedules make visits by the dentist an occasional occurrence. Consequently a dentist visiting a settlement would like to carry out as much of his work as possible in one sitting.

In children, multiple extractions or fillings under local anaesthesia not only are hard on the patient but severely tax the nerves of the dentist. Under such circumstances a short-acting general anaesthetic would be desirable, which could be safely administered even in the absence of preoperative preparation, which would allow enough time for the dental procedure to be carried out without fear of airway problems and other respiratory and circulatory complications, and which would not require skilled personnel for supervision during the postoperative period. Since Ketalar seemed to come close to such criteria, ${ }^{1}$ I undertook a trial with this agent during visits to Baffin Island in December 1968 and in March and November 1969.

Anaesthetics for dental surgery were given in three communities, and these represent three levels of health care facilities available in the Arctic:

1. Frobisher Bay (population 1,800) has a 28-bed federal government hospital, which was built in 1965 and is well equipped by modern standards, has a medical staff, and is adequately supplied with nursing personnel. Here anaesthetics for dentistry were given in the operating room or in the dental department. Except for limited recovery room space, the facilities for anaesthetic care, personnel, and equipment were comparable to those of any well run community hospital in Canada.

2. St. Luke's Hospital in Pangnirtung, a settlement of about 600 , is the oldest hospital in the eastern Arctic and is maintained by the Anglican Church. There has not been a resident physician for several years and care is provided by four experienced nurses. Here dental procedures were carried out in a portable dental chair in the operating room; suction and oxygen were available. Following the

"Department of Anaesthesia, University of Western Ontario, London, Canada. 


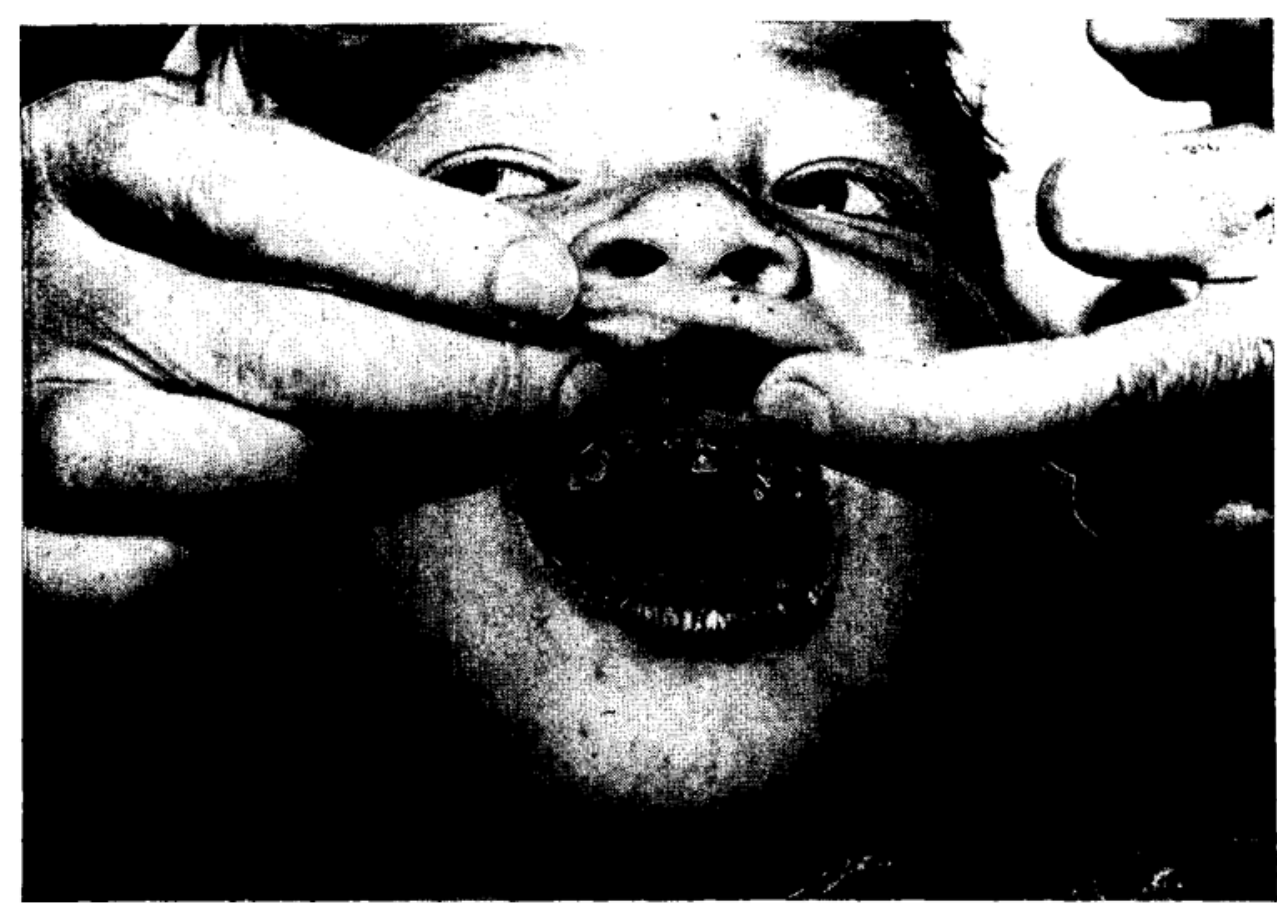

Figure I. A five-year-old boy with advanced caries and abscesses (Frobisher Bay).

dental procedure the children had to be carried through a lengthy narrow corridor to a make-shift recovery room (Fig. 2): four beds were tied together and supplied with railings to provide a large surface for multiple recovery. An experienced nurse and an Eskimo woman were in attendance.

3. Broughton Island, a settlement of 300 on the east coast of Baffin Island, north of the Arctic Circle, has only a small nursing station with one Public Health Nurse. Dentistry was carried out in the local school house, where one classroom was used as an operatory and an adjacent one as a recovery room. Suction was available only for the dental procedure and the compressor was a rather heavy burden on the electrical system and therefore used sparingly. The recovery area consisted of the tiled classroom floor; disposable diapers, paper towels, and paper bags were the only equipment available. The children were looked after by five Eskimo mothers who were the local (untrained) midwives and had volunteered for this occasion. Throughout the day they were often joined in this task by mothers or fathers of the children (Fig. 3).

\section{Procedure}

The children arrived one or two hours before surgery. No instructions regarding oral intake had been given to the parents. The children had been seen by a physician or by the Public Health Nurse some time before the day of surgery and were free of serious disease conditions; however, most children had nasal dis- 


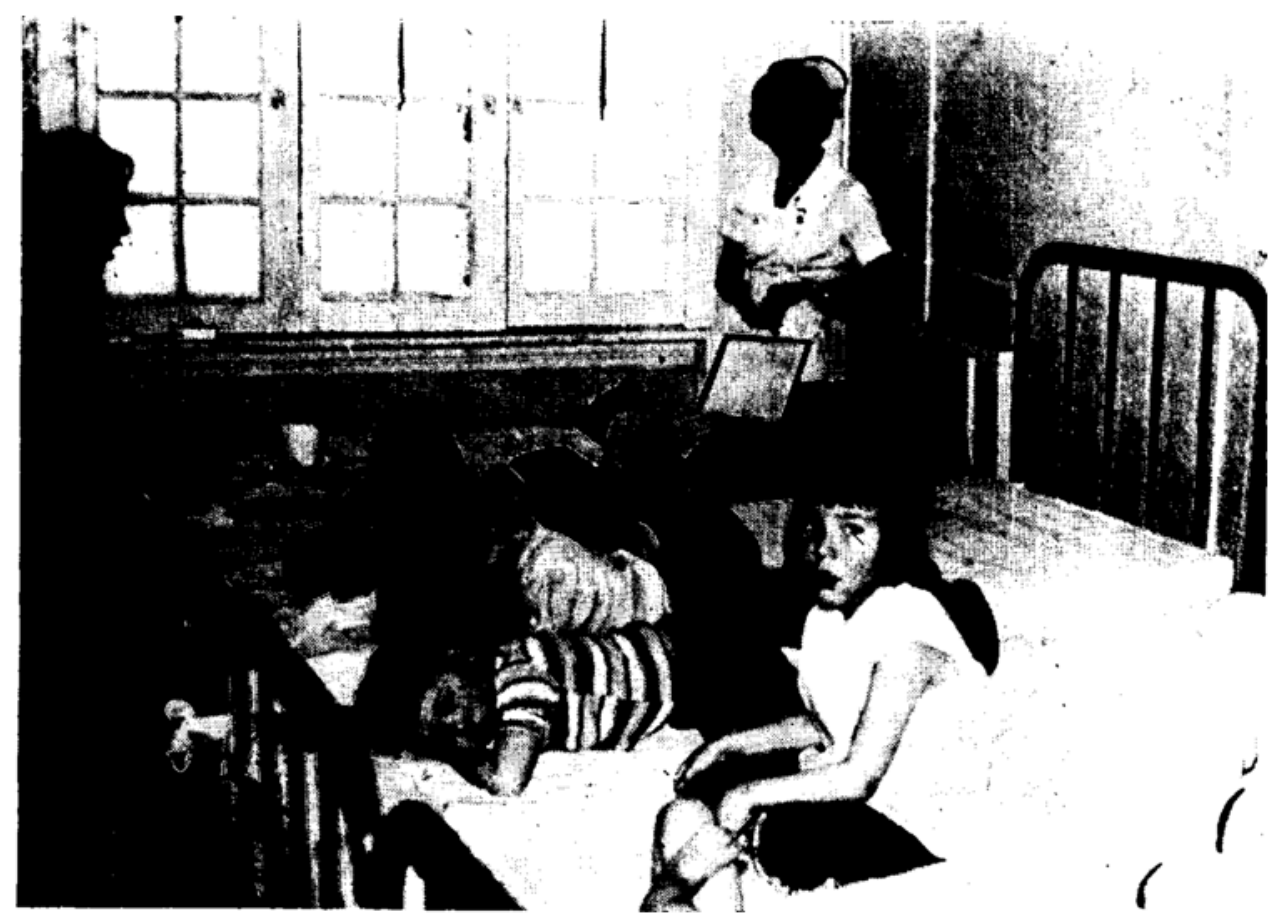

Figure 2. Recovery room (Pangnirtung). Patients are in various stages of recovery after Ketalar anaesthesia.

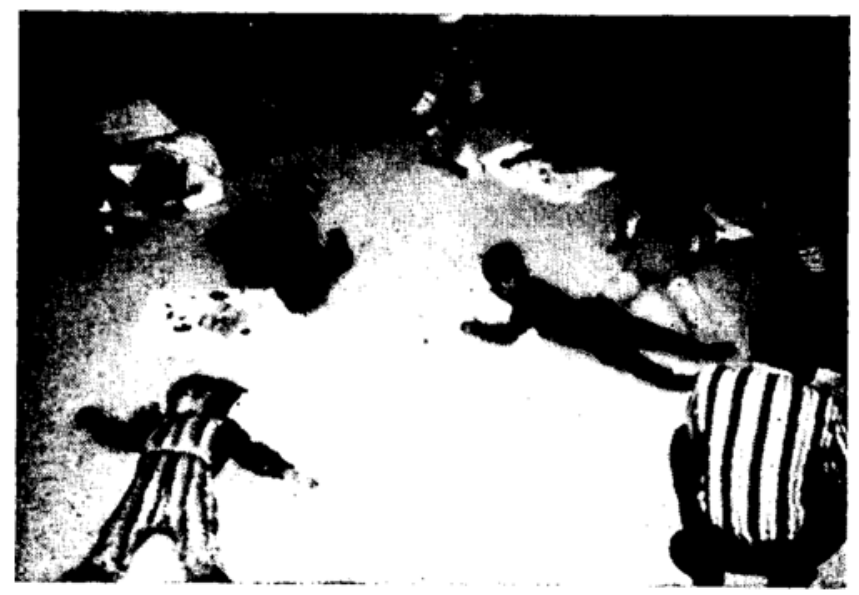

Ficure 3. Recovery area (Broughton Island). Children are recovering after Ketalar anaesthesia in a tiled floor, attended by lay helpers or parents.

charge and crusting and bronchitis; discharging ears and impetigo were common. None of the children had a significantly elevated temperature. Following admission the children were kept in a playroom and supervised by their parents, other Eskimo women, or a nurse (Fig. 4), and were kept busy until the time of surgery. No premedication was given. Only at the hospital in Frobisher Bay were the chil- 
dren undressed and provided with hospital pyjamas. Dental surgery was carried out in Frobisher Bay Hospital on an operating room table or in a dental chair in a semi-reclining position. In the two settlements a portable dental chair was used (Fig. 5). Ketalar was given in a single intravenous injection of $1 \mathrm{mg}$ per pound. When the dentist anticipated difficulty or a more lengthy procedure the needle was kept in place to allow a repeat injection. In the age group of two to three years only, an intramuscular injection of $4 \mathrm{mg}$ per pound was frequently preferred to avoid difficult venopunctures.

Following dental extractions, gauze packs were used to apply pressure to the open sockets until brisk bleeding had stopped. These were usually changed after two or three minutes and the child was carried to the recovery room with these gauze sponges in place. This caused no problem, and the children themselves expelled the gauze within the next few minutes.

In the recovery room the children were attended as described earlier; they were kept lying on their sides until they responded well. Where a nurse was available, an attempt was made to assess the time of return to consciousness and the child's ability to sit up unaided on command. The children were kept under supervision in the recovery area until they were able to stand and to dress themselves. They were then picked up by their parents or relatives or returned home by a hospital vehicle; in either case they had to be able to walk or ride sitting in a bumpy truck or on the back seat of a skidoo.

\section{RESULts}

A total of 310 children were anaesthetized with Ketalar for dental extractions; of these, 174 were treated in Frobisher Bay General Hospital, 69 in Pangnirtung, and 67 in Broughton Island. In five children conservative dentistry was carried out in addition to the surgery. The ages ranged from 2 to 15 years (Fig. 6); 93 per cent were Eskimo children, the rest Euro-Canadians. The average number of teeth extracted was four per child (range 1 to 15); the age distribution indicates that these were mainly deciduous teeth; however, many permanent teeth had to be extracted for advanced decay or for orthodontic indications.

\section{ANaesthesia AND Dental Surgery}

The operative procedure lasted on the average less than ten minutes, ranging from three to twenty minutes. The response to Ketalar is different from that seen with other anaesthetic agents. ${ }^{1-3}$ Within seconds after the intravenous injection the child becomes suddenly unresponsive and insensitive to superficial pain; there is an initial rapid nystagmus followed by a staring look of the open eyes. In many children the mouth would open easily; occasionally some force or a mouth gag was required to open the jaws initially, but thereafter the mouth usually stayed open. The tongue showed a normal position and exhibited some movement. The posterior part of the mouth seemed to be closed off by an approximation of the tongue and soft palate, preventing entrance of saliva and blood into the pharynx. Occasionally there was a swallowing motion and the rate of swallowing and 


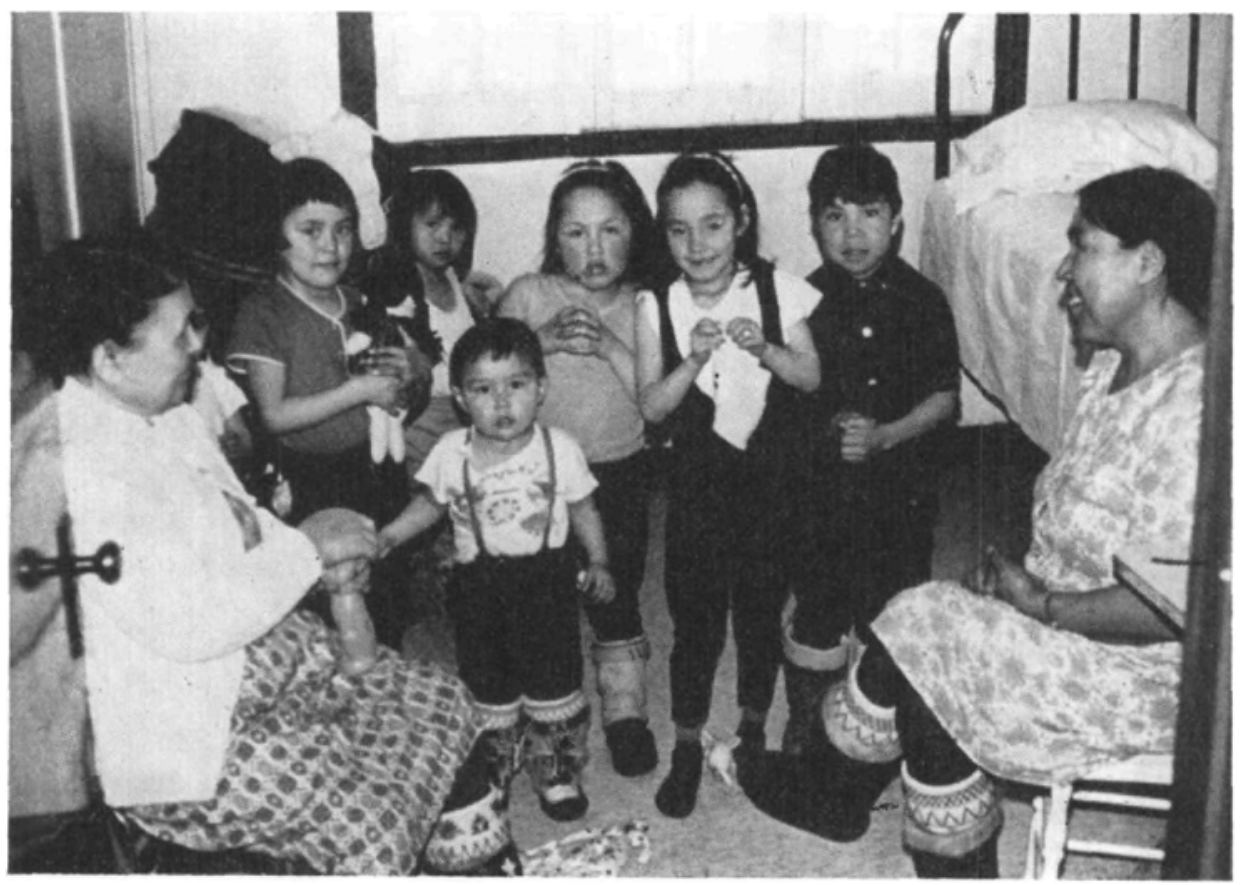

FIGURE 4. Preoperative waiting room (Pangnirtung).

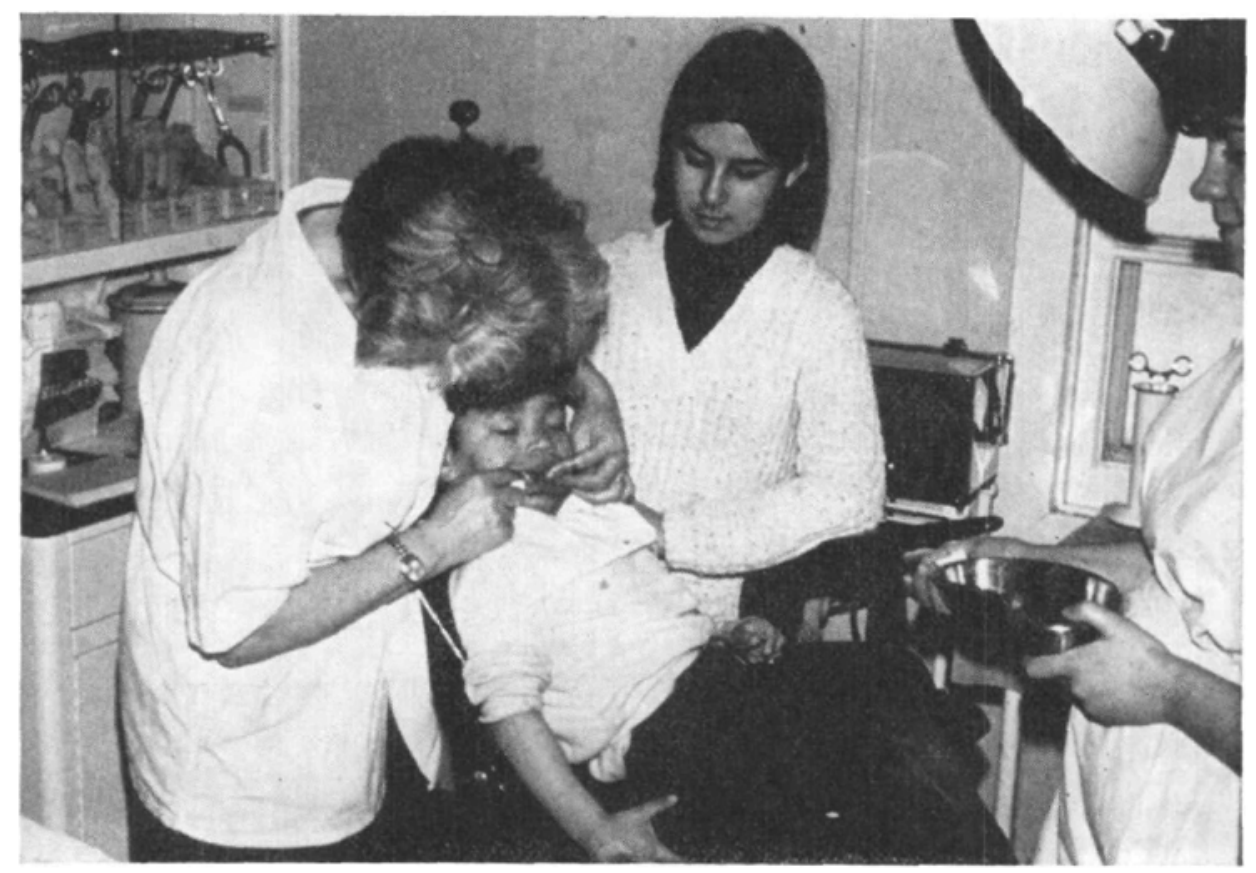

FIGUre 5. Operating room with portable dental chair (Pangnirtung). 


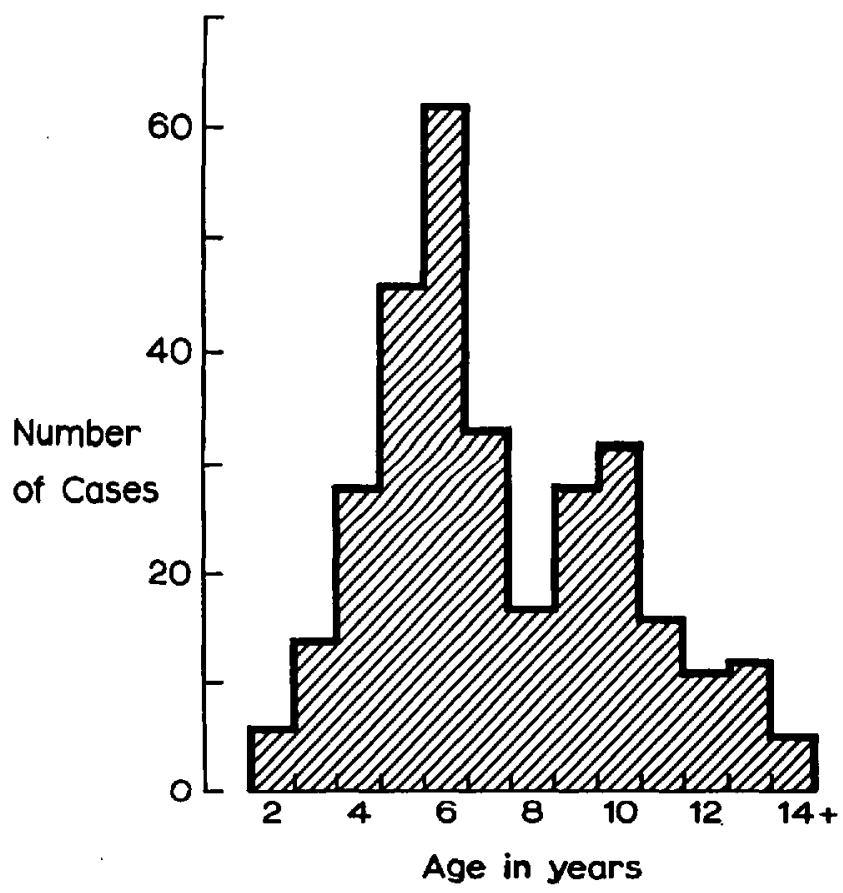

Figure 6. Age distribution of 310 children.

tongue movement seemed to increase as anaesthesia became lighter. Swallowing seemed to occur in response to accumulation of fluid in the posterior part of the mouth. A mouth pack was inserted in the first few children; later on this was only used for extensive procedures. Usually suction or gauze sponges were used to remove accumulations of blood and saliva.

The high degree of akinesia was remarkable; e.g., a hand placed on the armrest of the dental chair would usually remain unchanged throughout the procedure although the child did not actually hold onto the chair. Occasionally there were slight movements of the extremities, particularly as the anaesthesia lightened. There was usually no response to pain except in a few patients where difficult extractions were carried out towards the end of the period of anaesthesia; here the child would moan, take a deep breath, or actually cry out during severe pain. However, such responses were not accompanied by defence reactions such as withdrawal of the head, closing of the mouth or pushing with the arms; the child held his position and became quiet as soon as the painful stimulus ceased.

In five children one or several dental fillings were carried out combined with extractions. Here it was found that a single injection could provide a state suitable for conservative dental work for up to thirty minutes if most of the drilling was done during the early part of the procedure. The children, as they regained consciousness, responded willingly to commands to open and close their mouths and showed no objection to manipulation including even some drilling. However, if extractions had to be done following such conservative procedures a second injection of Ketalar was required. 


\section{Complications during anaesthesia}

The most remarkable feature of Ketalar was that the children retained a good airway. Manual support of the airway was required in two patients only: one 12 year-old had broken off his four front teeth while playing hockey. Cetavlon solution was used to wash out his mouth and some of the foaming solution got into his pharynx, causing choking and breath-holding; suction and a brief support of the airway remedied this quickly. In another five-year-old child, the difficult extraction of a molar had led inadvertently to a prolonged period where the child's jaw was pushed downward rather forcefully by the dentist, causing a mechanical obstruction of the airway with cyanosis. As soon as recognized, the jaw was pulled forward and adequate ventilation returned immediately.

One patient had a somewhat extended coughing spell towards the end of the procedure. A transient hiccough was seen in another. Blood and saliva never posed a problem; in spite of considerable accumulations, the children were able to breathe, and usually swallowed in response to the accumulation. Laryngospasm or excessive gagging or retching in response to suction of the posterior pharynx was noticeably absent.

An occasional patient showed a synchronized twitching of the arms, legs, head, and neck muscles, usually in succession but rarely more than five or six times. Respiration was not affected. Such myoclonic movements were observed in 18 children in this series; they were rather marked in three children of one Eskimo Euro-Canadian family. The course of anaesthetic and the recovery were not affected in any way.

A skin rash of a blotchy type on the face, upper chest, and arms was seen in several patients some minutes following the injection or early during the recovery and was always transient.

\section{Recovery}

On their arrival in the recovery room, almost all the children were unresponsive and quiet. In 121 children, a positive response to their environment, i.e., commands to open the eyes or mouth or respond to their name, occurred, on the average, 15 minutes after the single injection of Ketalar ( $1 \mathrm{mg}$ per pound of body weight). The return of sufficient muscular co-ordination to sit up unaided was considered another sign of recovery that could be assessed objectively: in 207 children, the average time between the intravenous injection of a single dose and the ability to sit up unaided on command was 29 minutes, with a range from 16 to 80 minutes; the longest period was in one ten-year-old girl who appeared to be responding well but stated that she could not sit up because she was unable to move. Recovery was considered complete ( 145 children observed) 90 minutes on the average after a single injection. At that time the children were able to stand and dress themselves alone or with minimal assistance.

Most children were quiet during recovery or showed only mild movements; only 4 per cent were sufficiently restless to require constant attention for any length of time. With multiple extractions postoperative pain was of some significance, and 43 per cent of the children were crying at some time during recovery; 
loud and excessive crying occurred in 14 per cent. There was a distinct impression that this response was influenced by the environment, e.g., one crying child seemed to initiate crying in other children who until then had recovered quietly.

\section{Complications during recovery}

Adequate observations about postanaesthetic vomiting were possible in 146 children who received Ketalar only; lack of observance precluded records in the smallest settlement and in some cases in Frobisher Bay Hospital when dentistry was interspaced with other surgery on the same day. Of the 146 children, 60 (or 41 per cent) vomited at least once during recovery (Table I). Twelve of these (or 8 per cent) had three or more episodes of emesis, of whom six were given Gravol because the tendency to vomit had persisted for several hours, in four throughout the night after oral surgery. It also appeared that there was a greater tendency to vomit following Ketalar in older children.

An attempt was made in the last 74 children in this series to influence the incidence of postanaesthetic emesis by giving drugs with antiemetic activity together with the intravenous injection. The agents available were scopolamine $\mathrm{HBr}$ (dosage per child, $0.1 \mathrm{mg}$ ), diphenhydramine $\mathrm{HCl}$ (Benadryl, $5 \mathrm{mg}$ ) and trimethobenzamide $\mathrm{HCl}$ (Tigan, $100 \mathrm{mg}$ ). These were injected mixed with the Ketalar in one syringe (Table II). Only scopolamine appeared to have a noticeable effect in preventing repeated vomiting.

Vomiting occurred only late in the recovery period when the children were responsive and almost always able to sit up. At the Frobisher Bay General Hospital a two-stage recovery procedure was used in 64 children, mainly to save personnel. The children were kept initially in a room next to the operating room until they were conscious and able to sit up and were then transferred to another room on the ward for the remainder of the recovery period. Only three patients vomited in the primary room where the average stay was about thirty minutes, and then at a time when they were just about ready to leave for the second room. On the other hand, several children vomited for the first time after they got on their feet and dressed themselves.

Fourteen children complained of headache; in four of these it was sufficiently severe and long-lasting (over an hour) that aspirin was given; this seemed to relieve it. Twelve of these children also vomited twice or more. Two children exhibited marked shivering and general stiffness. Another child was stiff to the point of plasticity, not unlike a true catatonic state at the end of surgery, and remained in this state for about ten minutes.

A delirium-like state was seen in twelve children during recovery. These children became quite talkative and entertained the recovery room staff; they were acting drunk, laughing or shouting, repeating endlessly words or phrases, pointing at nurses with the words, "you are funny, you are funny," etc. Some of these children were known to very lively and somewhat hyperactive, but with the Eskimo children any detail of their usual behaviour was difficult to ascertain on account of the language barrier and the restricted information available.

Diplopia was frequent and probably one of the longest-lasting effects; one older girl, fully responsive and sitting up about 90 minutes after the anaesthetic, was 
TABLE I

InCidence of Vomiting after Dental Anaesthesia WITH KETALAR

\begin{tabular}{lccc}
\hline & & \multicolumn{2}{c}{$\begin{array}{c}\text { Incidence of } \\
\text { postanaesthetic vomiting (\%) }\end{array}$} \\
\cline { 3 - 4 } $\begin{array}{c}\text { Age group } \\
\text { (years) }\end{array}$ & $\begin{array}{c}\text { Number of } \\
\text { patients }\end{array}$ & total & $\begin{array}{c}\text { repeated vomiting } \\
\text { (3 times or more) }\end{array}$ \\
\hline $2-4$ & 25 & 20 & 4 \\
$5-7$ & 67 & 34 & 3 \\
$8-10$ & 36 & 61 & 19 \\
11 or over & 18 & 56 & 11 \\
Total & 146 & 41 & 8 \\
\hline
\end{tabular}

TABLE II

Incidence of Vomiting after Dental Anaesthesia with Ketalar: EFFECT OF ANTIEMETIC AGENTS

\begin{tabular}{|c|c|c|c|}
\hline \multirow[b]{2}{*}{ Treatment } & \multirow[b]{2}{*}{$\begin{array}{l}\text { Number of } \\
\text { patients }\end{array}$} & \multicolumn{2}{|c|}{$\begin{array}{l}\text { Incidence of } \\
\text { postanaesthetic vomiting (\%) }\end{array}$} \\
\hline & & total & $\begin{array}{l}\text { repeated } \\
\text { (>3 times) }\end{array}$ \\
\hline $\begin{array}{l}\text { Nil } \\
\text { Scopolamine } \mathrm{HBr}, 1 \mathrm{mg} \text { i.v. } \\
\text { Diphenhydramine } \mathrm{HCl}, 5 \mathrm{mg} \text {, i.v. } \\
\text { Trimethobenzamine } \mathrm{HCl} 100 \mathrm{mg} \text {, i.v. }\end{array}$ & $\begin{array}{r}146 \\
30 \\
18 \\
26\end{array}$ & $\begin{array}{l}41 \\
20 \\
30 \\
27\end{array}$ & $\begin{array}{r}8 \\
0 \\
16 \\
4\end{array}$ \\
\hline Total & 220 & 36 & 7 \\
\hline
\end{tabular}

counting the adult people in the room at our request and counted each one of us twice.

\section{Long-term effects}

Although the children were left out of the control of the hospital fairly early, any disturbing after-effect of the anaesthetic would have come to our attention in the small communities. Several children were seen on the days following the Ketalar anaesthestic and they showed no fear or resentment of the dentist or the anaesthetist; on occasion we encountered groups of children laughing when they recognized us and pointing to their mouth or the site of the intravenous injection. One six-year-old, due to a clerical error, was brought back to the dentist three days after the Ketalar anaesthetic. He climbed into the dental chair without any fear and held out his hand for the injection. Two of the children required further extractions eight months after the initial one done under Ketalar anaesthesia; both were very calm and friendly and did not object to the procedure in any way.

\section{Discussion}

The clinical trial of Ketalar under conditions found in three Arctic communities again confirms the safety of this agent previously reported by other investigators. It also demonstrates that safe and efficient anaesthesia for oral surgery can be 
produced with this agent, even under relatively primitive conditions. The ease of administration, the excellent maintenance of the airway, obviating any need for airway support, and the lack of respiratory and circulatory depression certainly contributed to the safety and efficiency of this anaesthetic. Five to six children could easily be cared for in one hour. None of the presently used anaesthetic techniques in children, in my opinion, would have consistently provided satisfactory conditions for oral surgery equal to those obtained with Ketalar.

The aim of this study was to demonstrate that Ketalar could be used safely for this type of work in isolated areas without the need for the trained personnel and equipment usually available in a modern hospital. Although basic equipment for intubation and ventilation was available at all times it was never used. Even suction was not an absolutely essential item and was actually not used in many cases.

For dentistry there appears to be no need of any premedication. Salivation is slightly increased, but not enough to demand suppressive therapy in preparation for oral surgery. However, for conservative dentistry a dry mouth is a prerequisite, and premedication with a belladonna drug is mandatory.

Bleeding appeared to be more brisk than with other types of general anaesthesia, presumably due to the slightly higher blood pressure and greater peripheral blood flow with Ketalar. However, haemostasis was never a problem, and only one patient, in whom the gum had been torn during an extraction, had to be returned to the operating room about half an hour later to control the bleeding with a suture. No late haemorrhages were observed.

While the dentist and myself fully concurred with the reported excellent conditions that Ketalar provides for oral surgery, ${ }^{2,3}$ our experience regarding the postanaesthetic period differed to some extent from those of other observers. Certainly the return of responsiveness was rather rapid and the active reflexes contribute to the safety during this period; however, the recovery time to a point where the children were fully in control of their actions was longer than indicated by others. ${ }^{1,2}$ Even though the majority of our patients were able to stand and dress themselves after about 90 minutes, they were still quite noticeably affected by the drug.

Restlessness and crying were probably less common than one would expect with other types of anaesthetics. Even those children who exhibited a deliriumlike state could not really be considered a serious problem; they rather provided amusement for the nurses and for the Eskimo parents who were present. No adverse reactions or violent responses were seen.

Vomiting never occurred before the child had recovered sufficiently to move freely; almost always they were able to use a basin or a paper towel to wipe the mouth. The frequency was surprising: 41 per cent of the patients receiving only Ketalar vomited at least once and 8 per cent more than three times. Corssen $e t$ al. ${ }^{1,2}$ reported an incidence of less than 2 per cent in 1500 cases and of less than 6 per cent in 115 cases of oral surgery. Most of their patients were premedicated with scopolamine; however, in 30 of our cases the intravenous injection of $0.1 \mathrm{mg}$ of scopolamine only reduced the incidence of vomiting to 20 per cent, although there were no children with repeated emesis. Tigan and Benadryl given intravenously seemed to have little effect. Prolonged vomiting was successfully treated 
with Gravol suppositories. It would seem that the blood and saliva swallowed following oral surgery could be a major contributing factor; stimulation of the vomiting reflex from areas inside the mouth must also be considered to explain the much greater incidence of postanaesthetic vomiting in oral surgery. The children in the older age groups seemed to be more prone to postoperative vomiting, while race or the extent of the dental surgery bore no relation to this. The incidence of headache during recovery seemed sufficient to warrant consideration. For some children double vision can be disturbing and this should be explained to children's parents.

The dentist, who has to deal with these children under very difficult circumstances, was initially concerned that any bad experience of children with this type of anaesthetic could have very deleterious effects on their willingness in general to visit the dentist, and that it could also cause reluctance among the parents to send their children for dental care. These fears have not materialized; during our last visit we had the feeling that the parents were, if anything, more co-operative, and the children, who must have heard about the anaesthetic experience through their playmates, showed, in our opinion, less fear or resentment than on the previous visit. The two children who had come for a repeat anaesthetic eight months later were certainly the calmest and most co-operative children one could imagine in an operating room. Such evidence of acceptance is indirect; however, a more detailed assessment was not possible under the circumstances considering the language barrier and the different mentality of the Eskimo children.

\section{SUMMARY}

Three hundred and ten children were anaesthetized with Ketalar for dental surgery in three Arctic communities; in five, conservative dentistry was also carried out. In all cases Ketalar provided satisfactory conditions for the dental work required. The average duration of the surgical procedure was under ten minutes, and five to six children could be treated within an hour. On the average, four teeth were extracted per patient. The retention of protective reflexes, the excellent maintenance of the airway, respiration, and circulation provided a complicationfree period of surgery. Only two minor airway problems were encountered, easily manageable with manual support of the jaw and oropharyngeal suction.

Postoperatively the children responded to commands about fifteen minutes following the injection, and were able to sit up unaided after 29 minutes. They were discharged from the recovery room, able to care for themselves, 90 minutes on the average after the injection of a single dose. Most children were quiet during recovery and required little attention; marked restlessness was encountered in 4 per cent, and 14 per cent cried excessively. A state of delirium was observed in twelve children and this was usually of an amusing nature. Nearly 5 per cent complained of headache; double vision was frequently observed. Forty-one per cent of the children vomited at least once and 8 per cent more than three times; vomiting always occurred after the children were conscious and responsive; older children seemed to be more prone to emesis. The incidence of vomiting was some- 
what reduced when scopolamine $0.1 \mathrm{mg}$ was given intravenously with the induction of anaesthesia.

In this series, Ketalar proved to be a satisfactory and efficient anaesthetic agent for dental surgery, superior to conventionally used anaesthetic techniques. It appeared to be safe without the usual preoperative preparations and premedication, although it should only be administered by a competent anaesthetist.

\section{RÉSUMÉ}

Trois cent dix enfants ont été anesthésié au Kétalar pour chirurgie dentaire dans trois groupes de l'Arctique; chez cinq de ces enfants, on a pratiqué une chirurgie conservatrice. Dans tous les cas, le Kétalar a été satisfaisant pour le travail dentaire requis. La durée moyenne des interventions a été de moins de dix minutes et cinq ou six enfants ont été traités durant près d'une heure. En moyenne, on a extrait quatre dents par malade. La conservation des réflexes protecteurs, l'excellent maintien du passage de l'air, de la respiration et de la circulation ont fait que la chirurgie a été exempte de complications. On n'a ou que deux problèmes mineurs quant au libre passage de l'air dans les voies respiratoires, problèmes facilement réglés par le support manuel de la machoire et par l'aspiration oro-pharyngienne.

Après l'opération, les enfants exécutaient les ordres environ quinze minutes après l'injection, et ils pouvaient s'asseoir seuls après vingt-neuf minutes. Ils recevaient leur congé de la salle de réveil, capables de se suffire à eux-mêmes, en moyenne 90 minutes après l'injection d'une dose unique. La plupart des enfants furent tranquilles durant la période de réveil et ils requéraient peu de surveillance; on a noté une agitation marquée dans 4 pour cent des cas et 14 pour cent ont pleuré plus que de raison. Douze enfants ont présenté du délire, ce qui généralement, a été plutôt amusant. Près de 5 pour cent se sont plaint de céphalée; on a fréquemment observé de la double vision. Quarante et un pour cent des enfants ont vomi au moins une fois, et 8 pour cent plus de trois fois; les vomissements se sont toujours produits après le retour de la conscience et de la sensibilité; les enfants plus agés ont semblé plus inclins à vomir. La fréquence des vomissements a été quelque peu diminuée lorsqu'on a donné de la scopolamine $(0.1 \mathrm{mg})$ par voie veineuse en même temps que l'induction.

Dans cette série, le Kétalar s'est avéré un agent anesthésique satisfaisant et efficace pour la chirurgie dentaire, et supérieur aux techniques anesthésiques généralement en usage. Il a semblé sûr sans les préparations et prémédications préopératoires usuelles, bien qu'il ne doive être administré que par un anesthésiste compétent.

\section{ACKNOWLEDGMENTS}

I should like to express my appreciation to Dr. Ruth Horwood, the only dentist on Baffin Island, and to her husband, Dr. Don Horwood, the Medical Zone Director, whose co-operation and support made this study possible. The enthusiasm of Dr. C. A. Thompson for providing medical help in the Arctic region initiated 
these trips and my thoughts to take Ketalar along to provide dental anaesthesia. I am grateful to Dr. G. R. Butler, Regional Director of the Department of National Health and Welfare, who made the working arrangements and provided funds for Dr. A. Parnell, Professor of Oral Surgery, Faculty of Dentistry, University of Western Ontario, to join me on the last journey. The help and co-operation of the nursing staff of the Frobisher Bay General Hospital and the excellent support from Miss Thelma Benham and her staff at St. Luke's Anglican Hospital in Pangnirtung, are gratefully acknowledged. Special thanks should go to the Public Health Nurse in Broughton Island, Miss Jean Taylor, and to the Eskimo women who volunteered for the recovery room and who provided superb care for these children. Ketalar was supplied by Parke, Davis and Company, Ann Arbor, Michigan.

\section{REFERENCES}

1. Conssen, G.; Mryasaka, M.; \& Domino, E. F. Changing Concepts in Pain Control during Surgery: Dissociative Anesthesia with CI-581-A Progress Report. Anesth. \& Analg. 47: 746 (1968).

2. Corssen, C.; Hayward, J.; Gunter, J. W.; \& Groves, E. H. Ketamine (CI-581): A New Parenteral Anaesthetic for Oral Surgery. J. Oral Surg. 27: 627 (1969).

3. Stocker, L. Klinische Erfahrungen mit Ketamine bei Eingriffen im Zahn-, Mund- und Kieferbereich. Anaesthesiology and Resuscitation, volume 40: Ketamine. Ed. Kreuscher. Berlin, Heidelberg, New York: Springer Verlag (1969). 